compared with other methods of examination for the estimation of glucose in saccharine urines.

Appended for reference are given the parts per 1,000, and the percentages (grains by weight in 100 minims) corresponding to the number of grains per ounce ( 480 minims)

The former is calculated by dividing the number of grains per $o z$. by 0.4375 . The latter by multiplying the number of grains per ounce by $\frac{10}{4}$, a result of simple proportion.

The coloured test glasses in a pocket-case can be obtained from Messrs. Down Brothers, St. Thomas's Street, Borough S.E.

\begin{tabular}{c|c|c||c|c|c}
\hline $\begin{array}{c}\text { Grains } \\
\text { per oz. }\end{array}$ & $\begin{array}{c}\text { Parts per } \\
1,000 .\end{array}$ & $\begin{array}{c}\text { Grains per } \\
100 \text { minims. }\end{array}$ & $\begin{array}{c}\text { Grains } \\
\text { per oz. }\end{array}$ & $\begin{array}{c}\text { Parts per } \\
1,000 .\end{array}$ & $\begin{array}{c}\text { Grains per } \\
100 \text { minims. }\end{array}$ \\
\hline 1 & 2.23 & 0.208 & 11 & 25.14 & 2.29 \\
2 & 4.57 & $\begin{array}{c}0.416 \\
\text { (say p.c.) } \\
0.625\end{array}$ & 12 & 27.40 & -2.50 \\
3 & 6.85 & 13 & 29.71 & 2.70 \\
4 & 9.14 & 0.853 & 14 & 32.00 & 2.91 \\
5 & 11.42 & 1.04 & 15 & 34.28 & 3.12 \\
6 & 13.71 & 1.25 & 16 & 36.57 & 3.32 \\
7 & 16.00 & 1.45 & 17 & 38.85 & 3.54 \\
8 & 18.28 & 1.66 & 18 & 41.14 & 3.75 \\
9 & 20.57 & 1.87 & 19 & 43.42 & 3.95 \\
10 & 22.85 & 2.08 & 20 & 45.71 & 4.16 \\
& & (say 2 p.c.) & & & \\
\hline
\end{tabular}

\section{A CASE OF CYCLOPIA.}

BY

DANIEL DOUGAL, M.D.,

HONORARY ASSISTANT SURGEON FOR WOMEN, NORTHERN EOSPITAL: PATHOLOGIST, ST. MARY'S HOSPITALS, MANCHESTER,

AND

T. MILNES BRIDE, M.D.,

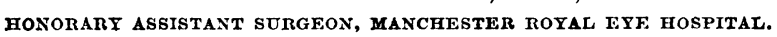

THE essential features of this malformation are the absence of a well-formed nose in its natural position, the presence of one orbit in the middle line of the face containing a single eye or one showing varying grades of duplicity, and defective development of the upper part of tho face and anterior portion of the brain, these abnormalities being the result of incomplete development of the fronto-nasal process with approximation and fusion in the middle line of the two superior maxillary processes.

As regards the frequency of its occurrence, Hannover has collected 109 cases in the human subject, so that it may be regarded as a comparatively frequent type of monstrosity, althongh sufficiently rare to warrant the publication of any examples which may occur.

The nother of the case here reported was admitted to St. Mary's Hospitals in October, 1912, being then in the seventh month of her pregnancy, and suffering from antepartum haemorrhage due to placenta pracvia. She had previously given birth to eleven children, none of whom presented any abnormal features.

\section{Description of Cycrops.}

The child, a male, was stillborn, and weighed $5 \div \mathrm{lb}$. The head was proportionately large owing to the presence of well-marked hydrocephalus; in the centre of the face was a diamond-shaped opening, bounded above and below by the fused upper and lower lids respectively, and enclosing what appeared to be a single eyeball provided with two corneae. Immediately above this opening, and jutting forwards from the middle line, was a cylindrical projection, the proboscis, and running outwards from the base of the latter were two elevations, representing the eyebrows. Beneath the orbit was a deep sulcus running transversely across the face, whilst below this was the upper lip, devoid of any trace of philtrum, but otherwise well developed. The face showed no other abnormality, the ears and lower jaw being well formed.

\section{The Eye.}

This organ, contained in a single large orbit, was found to be composed of two globes fused together in the middle line and having a median groove above and below. All the extrinsic muscles were found to be present with the exception of the internal recti. On the anterior surface of either half of the globe was. a complete cornea through which could be seen the iris enclosing a circular pupil, the portion of sclera separating the two corneae was covered with conjunctiva, whilst overlying the middle portion of this was a tough fibrous band half an inch in width and running from the proboscis above to the junction of the fused lids below. A horizontal section of the organ showed that the globes were complete units, and perfect in all component parts except at their juncture, where the sclerotic and choroid 'were found to be absent, that the retinae were thrown into folds not apparently due to mechanical detachment, and that the optic nerves were fused except at the point of expansion into the retinae, where there was sorne evidence of separation. As regards the lids, all four lacr ymal papillae were present.

\section{The Nasal Apparatus.}

The proboscis was situated immediately above the orbit in the position of the glabella, and measured 11 in. in length by $\frac{3}{4}$ in. in breadth; in shape it was irregularly cylindrical, some what constricted at its proximal end and provided with a depression at its free extremity; in the floor of this depres.

sion was a small opening leading into a large central cavity lined with mucous membrane and containing a quantity of mucus. The proboscis was some wh at rigid from the presence of a cartilaginous plate beneath the floor of the cavity, and had a covering of skin resembling that of the face. This structure represents the soft parts of the nose, which are in an abnormal position from the

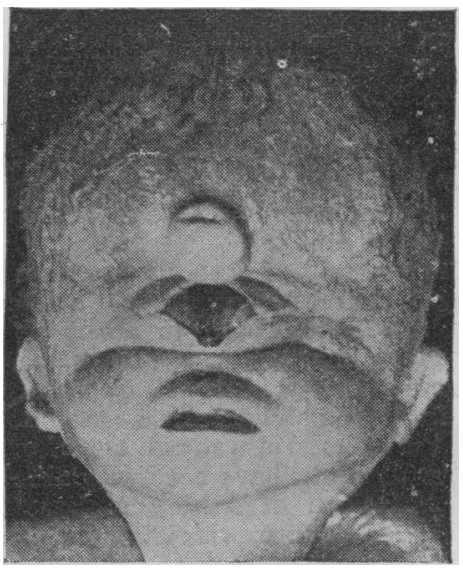
approximation of the superior maxillary bones. The following bones normally connected with the structure of the nose were absent: the ethmoid, presphenoid, vomer, inferior turbinate, nasals, lacrymals, and premaxillae.

A mesial section through the skeleton of the face showed the palate bones fused together; in front of this the superior maxillae were separated by a thin membrane, deficient above and below, supposed to represent the nasal mucosa, while further forward they were firmly united to form the alveolar margin. The vault of the palate was narrow and not fissured, the soft palate and uvula were well developed, the latter being notched at its extremity, whilst belind was a rounded cul-de-sac, into which opened the Eustachian tubes. The upper jaw contained six tooth germs.

\section{The Cranium and Brain.}

The ossification of the cranium was not deficient, but the sutures were increased in width, owing to the hydrocephalic condition, the anterior fontanelle being much larger than normal. The anterior cranial fossa was very small, the middle fossa deep and narrow, and the posterior fossa well formed.

The brain was not. sufficiently well preserved for a careful examination to be made, but there appeared tc be a single hemisphere, which was flattened out by the large hydrocephalic sac situated above it; the convolu. tions and fissures were incompletely marked, and the falx cerebri absent.

No other malformations were found, the child being well developed with the exception of the abnormalities above described.

With regard to the type of cyclopia represented by this specimen, the presence of the proboscis places it in that designated by Saint-Hilaire " rhinocephalus," as distinct from the cyclocephalic type. in which this organ is absent. 